\title{
Physiological Integration Ameliorates Negative Effects of Water Stress in Salt-sensitive 'C198' Common Bermudagrass
}

\author{
Erick Amombo and Longxing $\mathrm{Hu}$ \\ Key Laboratory of Plant Germplasm Enhancement and Specialty Agriculture and Wuhan Botanical \\ Garden, Chinese Academy of Sciences, Wuhan, Hubei 430074, China; and the University of Chinese \\ Academy of Sciences, 19 Yuquan Road, Beijing 100049, China
}
Jibiao Fan and Zhengrong Hu
Key Laboratory of Plant Germplasm Enhancement and Specialty Agriculture and Wuhan Botanical Garden, Chinese Academy of Sciences, Wuhan, Hubei 430074, China; and the University of Chinese Academy of Sciences, 19 Yuquan Road, Beijing 100049, China

\author{
Jinmin $\mathbf{F u} \mathbf{u}^{1}$ \\ Key Laboratory of Plant Germplasm Enhancement and Specialty Agriculture and Wuhan Botanical \\ Garden, Chinese Academy of Sciences, Wuhan, Hubei 430074, China
}

\begin{abstract}
Additional INDEX words. Cynodon dactylon, ramets, drought, antioxidant enzymes
Abstract. Clonal plants can consist of connected individual ramets that enhance resource sharing through physiological integration. This integration enables the whole clone to tolerate environmental stresses. The objective of this research was to investigate the effects of physical ramet connections on the integration of antioxidant enzymes in clonal common bermudagrass (Cynodon dactylon) growing under heterogeneously distributed water; i.e., nonuniform distribution of water due to $20 \%$ polyethylene glycol (PEG 6000) treatment on some ramets and not others. The bottom, middle, upper and three fragments of clonal common bermudagrass were subjected to $20 \%$ PEG 6000 with water potential of -1.8 MPa to induce heterogeneous and homogeneous drought stress. The control was not treated with $20 \%$ PEG 6000. Within the heterogeneous treatment, water stressed clonal fragments generally had higher leaf and root antioxidant enzyme activities with respect to superoxide dismutase, catalase, peroxidase (except for root peroxidase). There was no difference in antioxidant enzyme activity within the connected clonal ramets for homogeneous treatment; i.e., three connected ramets treated with $20 \%$ PEG 6000. Osmotically stressed clonal fragments under heterogeneous environments had a lower level of malonaldehyde (MDA) compared with those in homogeneous regimes. The antioxidant enzyme integration was affected by directionality and water availability contrast. This was indicated by significant decline in MDA levels within the heterogeneous treatments as compared with homogeneous treatment, which suggested reduced lipid peroxidation. These results suggested that ramet connections facilitate integration of antioxidant enzymes within clonal plants growing in heterogeneously available water. Enzymes were integrated from clonal fragments growing in water sufficient environment to those in water stressed regimes. This enhanced reactive oxygen species scavenging capacity of the entire clone hence improved drought tolerance.
\end{abstract}

Drought is a major abiotic stress limiting plant productivity in arid and semiarid regions (Boyer, 1982; Jaleel et al., 2009). Drought causes stomatal closure and forms superoxide anion radicals (Kuo and Kao, 2003). Eventually, drought generates more reactive oxygen species (ROS) such as hydrogen peroxides $\left(\mathrm{H}_{2} \mathrm{O}_{2}\right)$ and hydroxyl radicals $\left({ }^{\circ} \mathrm{OH}\right)$, and perturbs the equilibrium between ROS scavenging and production (Carvalho and Helena, 2008). The ROS may lead to protein site specific oxidative damage, lipid peroxidation, bp modifications and sugar fragmentation in nucleic acids, and eventually cell death (Palmer and Paulson, 1997). Plants have evolved different enzymatic and nonenzymatic scavenging mechanisms for ROS regulation. Scavenging enzymes includes superoxide

Received for publication 25 Mar. 2015. Accepted for publication 6 May 2015. This work was financially supported by the Young Scientists Fund of the National Natural Science Foundation of China (Grant 31101563), China-Africa Center for Research and Education, CAS (SAJC201325), and the National Natural Science Foundation of China (Grant 31272194).

${ }^{1}$ Corresponding author. E-mail: jfu@wbgcas.cn. dismutase (SOD), catalase (CAT), and guaiacol peroxidase (POD). The ROS scavenging mechanisms have been confirmed in almost all cellular compartments to enhance plant survival under stress (Mittler et al., 2004). Differential genomic and proteomic screening of gransden moss (Physcomitrella patens) indicated that drought stress led to up regulation of many genes for antioxidative enzyme defense. This up regulation suggests the necessity of antioxidative system in protecting cells against damage (Gao et al., 2008; Wang et al., 2008).

Clonal growth (i.e., ramets connected by stolons) is widespread in the plant kingdom (Kliměs et al., 1997). This kind of reproduction implies that a clonal system is more likely to experience spatial heterogeneity than nonclonal plants (Roiloa and Retuerto, 2006). Many studies have revealed that clonal plants under heterogeneous environments display higher capacity for integration (Hutchings and de Kroon, 1994) and labor division (Alpert, 1991; Alpert and Stuefer, 1997; D’Hertefeldt and Jónsdóttir, 1994; Lau and Young, 1988; Lin et al., 2006; $\mathrm{Wu}$ et al., 2007). Findings from studies with split root systems indicated that heterogeneously available water enhanced plant 
growth in tomato [Solanum lycopersicum (Tabatabaie and Gregory, 2004)], bluegreen saltbush [Atriplex nammularia (Bazihizina et al., 2009)], and cucumber [Cucumis sativus (Sovenneveld and de Kreij, 1999)]. Stolons and rhizome connections in clonal plants facilitate translocation of resources and nonresources. This enables the entire clone to rapidly colonize and exploit higher stress patches that would otherwise be unexploitable by independent plants (Silander and Picala, 1990).

Clonal common bermudagrass is characterized by the production of genetically identical offspring ramets that may often remain connected for considerable time to the parent. Previous studies under small-scale controlled environments have indicated that clonal common bermudagrass is more tolerant to water stress than many agricultural crops (Maas and Hoffman, 1977; Marcum and Murdoch, 1994). Any form of clonal integration irrespective of substances shared among the ramets uses the vascular system for transportation within clonal plants. Therefore, nonresource integration is likely to follow the same principle. However, plants have different response mechanisms to resource and nonresources (Roiloa and Hutchings, 2013). Ramet connections allow easy translocation of resources (e.g., water and nutrients) (Chapman et al., 1991; Kemball and Marshall, 1995; Oborny et al., 2000; Shumway, 1995). More attention has been given to integration in clonal plants in response to environmental heterogeneity using simple contrast models (Parker and Salzman, 1985; Roiloa and Retuerto, 2005). Ramets of clonal plants experience more complex habitats under natural environments. Therefore, clear comprehension of the integration of antioxidant enzymes would enhance understanding of osmotic stress tolerance mechanisms in this clone.

We hypothesize that antioxidant enzymes are translocated from ramets growing under favorable conditions to their connected osmotically stressed neighbors. Therefore, the objective of this study was to investigate the effect of water stress on the antioxidant defense system in 'C198' common bermudagrass. In this study, we examine the behavior of antioxidant enzymes in individual ramets independently and then scaled to the whole clone interconnected level of common bermudagrass.

\section{Materials and Methods}

Plant materials and growth conditions. This experiment was conducted in the Wuhan Botanical Garden, Chinese Academy of Sciences, China from Jan. to Oct. 2014. We employed a wild-type, salt-sensitive common bermudagrass designated ' $\mathrm{C} 198$ ' as plant material. Uniform stolons consisting of three nodes were planted in plastic pots filled with sand (2 peat soil:1 sand, v/v) (Hu et al., 2011). Plants were watered everyday and fertilized with half-strength Hoagland nutrient solution $(11 \mathrm{~N}-1.3 \mathrm{P}-8.3 \mathrm{~K})$ twice per week (Hoagland and Arnon, 1950). The plants were allowed to grow in the greenhouse with a temperature regime of $30 / 25^{\circ} \mathrm{C}$ (day/night), photosynthetically active radiation $(P A R)$ levels of $1100 \mu \mathrm{mol} \cdot \mathrm{m}^{-2} \cdot \mathrm{s}^{-1}$ at canopy height for $14 \mathrm{~h}$. Full canopy (i.e., 100\%) was established after 2 months, and then the plants were transferred to a hydroponics system with Hoagland nutrient solution for $5 \mathrm{~d}$ for adaptation under new growth conditions in controlled-environment growth chambers (HP300GS-C; Ruihua Instruments, Wuhan, China). Plants were allowed to adapt to this nutrient solution. During this period, the plant shoots were hand-clipped at a $6 \mathrm{~cm}$ height, and roots were clipped back to the bottoms of the pots at the beginning of the $20 \%$ polyethylene glycol treatment to allow the plants to reach full maturity and develop uniform and equal size roots and shoots.

Treatment AND EXPERIMENTAL DeSign. After adaptation, the plants were exposed to $20 \%$ PEG $6000(-1.8 \mathrm{MPa})$ for 2 weeks. The samples were arranged in a randomized complete block design with three biological replicates. Clonal common bermudagrass was subjected to five 20\% PEG 6000 treatments. The treatments were designated as WPW to indicate treatment on the middle ramet, WWP to indicate treatment on the upper ramet, $\mathrm{PWW}$ to indicate treatment on bottom ramet, PPP to indicate treatment on all three ramets, and WWW to indicate no treatment thus acting as the control (Fig. 1). The leaves and roots from each ramet were simultaneously harvested after 2 weeks, put in liquid nitrogen immediately and stored in $-70{ }^{\circ} \mathrm{C}$ for subsequent laboratory analysis. The roots were thoroughly washed with deionized water to remove any contaminants.

Measurements. To determine antioxidant enzyme activities and malonaldehyde levels, $0.25 \mathrm{~g}$ leaves were homogenized with mortar and pestle in liquid nitrogen with phosphate buffer (150 mM, pH 7.0). The homogenate was centrifuged at 15,000 $g_{\mathrm{n}}$ for $20 \mathrm{~min}$ at $4{ }^{\circ} \mathrm{C}$. The resulting supernatant was used to measure different antioxidant enzymes, soluble protein content and MDA content.

The SOD activity (EC 1.15.1.1) was measured by determining its ability to inhibit the photochemical reduction of nitroblue tetrazolium chloride [NBT (Becana et al., 1986)]. The assay mixture contained $0.1 \mathrm{~mL}$ of $50-\mathrm{mmol} \cdot \mathrm{L}^{-1} \mathrm{PBS}$, $1.125 \mathrm{mmol} \cdot \mathrm{L}^{-1} \mathrm{NBT}, 0.1 \mathrm{~mL}$ of $60-\mu \mathrm{mol} \cdot \mathrm{L}^{-1}$ riboflavin, and $195 \mathrm{mmol} \cdot \mathrm{L}^{-1}$ methionine. The tubes were shaken and placed under 13,000-lux fluorescent lamp for $30 \mathrm{~min}$ at $25^{\circ} \mathrm{C}$. The nonilluminated reaction mixture was used as blank and the absorbance was read at $560 \mathrm{~nm}$. One unit of SOD was defined as the amount of enzyme required for 50\% NBT inhibition.

Lipid peroxidation was determined by measuring the amount of MDA following the Heath (1968) protocol, with slight modifications. Enzyme solution $(1.0 \mathrm{~mL})$ was added to $2 \mathrm{~mL}$ of reaction solution containing $20 \%$ TCA and $0.5 \%$ TBA. The mixture was heated at $95{ }^{\circ} \mathrm{C}$ for $30 \mathrm{~min}$, cooled on ice water, and centrifuged at $14,000 \mathrm{~g}_{\mathrm{n}}$ at $20^{\circ} \mathrm{C}$ for $20 \mathrm{~min}$. The absorbance was measured at $532 \mathrm{~nm}$. The value at $600 \mathrm{~nm}$ was subtracted to obtain unspecific turbidity. The MDA amount was calculated based on adjusted absorbance and extinction coefficient of $155 \mathrm{~nm} \cdot \mathrm{cm}^{-1}$ using the formula: MDA (micromoles per gram) $=$ $[(\mathrm{OD} 532-\mathrm{OD} 600) \times L] /(l \times \epsilon \times \mathrm{FW})$, where $L$ indicates the volume of the extract solution, $l$ indicates thickness of the cuvette,

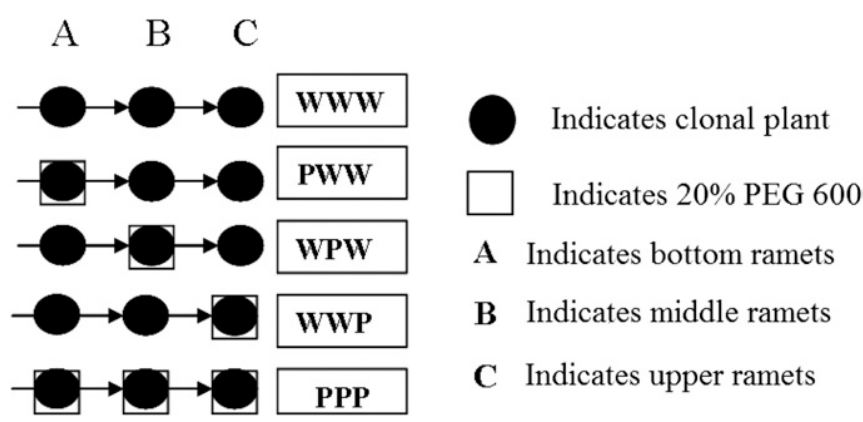

Fig. 1. Polyethylene glycol (20\% PEG 6000) treatment layout on clonal common bermudagrass connected by ramets: WWW $=$ control; PWW, WPW, and WWP indicate heterogeneous treatments where $\mathrm{PWW}=$ bottom, $\mathrm{WPW}=$ middle, and WWP $=$ upper ramets. PPP indicates homogeneously treated ramets. Arrow points distal. 
$\epsilon$ represents the molar absorption coefficient of $155 \mathrm{mM} \cdot \mathrm{cm}^{-1}$, and FW is the fresh weight of the leaf tissue.

The POD activity (EC 1.11.1.7) was determined based on the guaiacol oxidation by assessing an increase in absorbance at $460 \mathrm{~nm}$. The reaction mixture contained $1.85 \mathrm{~mL}$ of 0.1 sodium acetate buffer [HAC-NaAC ( $\mathrm{pH} 5.0)$ ], $1 \mathrm{~mL}$ of guaiacol, $100 \mu \mathrm{L}$ of $0.75 \% \mathrm{H}_{2} \mathrm{O}_{2}$, and $50 \mu \mathrm{L}$ enzyme extraction. The mixture was vortexed and absorbance read at $460 \mathrm{~nm}$ once every minute within the first $3 \mathrm{~min}$. One POD activity was defined as the absorbance change of one unit per minute per milligram protein.

CAT activity (EC 1.11.1.6) was determined following the Aebi (1984) protocol with slight modifications. The reaction mixture contained $0.1 \mathrm{~mL}$ enzyme extract, $1.90 \mathrm{~mL}$ of $50-\mathrm{mmol} \cdot \mathrm{L}^{-1}$ PBS (pH 7.0). Absorbance was read at $240 \mathrm{~nm}$ once every minute within the first $3 \mathrm{~min}$. One CAT activity was defined as the absorbance change of 0.01 units per minute and the activity expressed on soluble protein content.

Total soluble protein content was determined using Coomassie brilliant blue following the method described by Bradford (1976). All spectrophotometric analyses were conducted using a spectrophotometer [ultraviolet-2600; UNICO (Shanghai) Instruments, Shanghai, China].

STATistical analysis. All results from the experiment were expressed as mean of three replicates. The data were subjected to one-way analysis of variance using SPSS (version 16.0; IBM Corp., Armonk, NY) to compare the means. Duncan's test was used for multiple comparison at $P \leq 0.05$ level between treatment and ramets.

\section{Results}

LIPID PEROXIDATION. There was no difference in the mean leaf MDA levels within the heterogeneous treatments (i.e., PWW, WPW, and WWP) (Table 1). The 'C198' common bermudagrass leaves had a higher MDA level in the homogeneous (PPP) regime vs. control (WWW) and heterogeneous regimes (Table 1). The WWW treated plants contained the least MDA (Table 1). There was no difference in MDA levels within the connected ramets of homogeneous (PPP) and control (WWW). PEG 6000 treated fragments generally had more MDA compared with other two fragments for heterogeneous

Table 1. Effects of contrast level of water availability on leaf physiological parameters in clonal common bermudagrass.

\begin{tabular}{lccccc}
\hline & \multicolumn{5}{c}{ Treatment $^{\mathrm{y}}$} \\
\cline { 2 - 6 } Parameters & WWW & PWW & WPW & WWP & PPP \\
\hline MDA $\left(\mu \mathrm{mol} \cdot \mathrm{g}^{-1} \mathrm{FW}\right)$ & $10.3 \mathrm{c}^{\mathrm{x}}$ & $15.8 \mathrm{~b}$ & $14.9 \mathrm{~b}$ & $13.4 \mathrm{~b}$ & $19.7 \mathrm{a}$ \\
SOD $\left(\mathrm{U} \cdot \mathrm{mg}^{-1}\right.$ protein) & $10.9 \mathrm{a}$ & $13.1 \mathrm{a}$ & $11.7 \mathrm{a}$ & $11.9 \mathrm{a}$ & $12.9 \mathrm{a}$ \\
CAT $\left(\mathrm{U} \cdot \mathrm{mg}^{-1}\right.$ protein) & $28.2 \mathrm{~b}$ & $36.7 \mathrm{ab}$ & $35.7 \mathrm{ab}$ & $35.1 \mathrm{ab}$ & $49.8 \mathrm{a}$ \\
POD $\left(\mathrm{U} \cdot \mathrm{mg}^{-1}\right.$ protein) & $13.8 \mathrm{a}$ & $8.7 \mathrm{~b}$ & $6.9 \mathrm{bc}$ & $8.3 \mathrm{~b}$ & $6.5 \mathrm{c}$
\end{tabular}

${ }^{\mathrm{z}} \mathrm{MDA}=$ malonaldehyde; $\mathrm{SOD}=$ superoxide dismutase; $\mathrm{POD}=$ peroxidase CAT $=$ catalase .

${ }^{\text {y }}$ Polyethylene glycol (20\% PEG 6000) treatment layout on three connected ramets: WWW = control; PWW, WPW, and WWP indicate heterogeneous treatments where $\mathrm{PWW}=$ bottom; WPW = middle; and WWP = upper ramets. PPP indicates homogeneously treated ramets. $\mathrm{W}$ is nutrient solution while $\mathrm{P}$ is $20 \%$ PEG 6000 resolved in nutrient solution.

${ }^{x}$ Means in a row for each parameter followed by the same letter are not significantly different based on Duncan's test $(P \leq 0.05)$. treatment regimes. The middle ramets exhibited a higher level of MDA than the upper and bottom ramets of PWW and WWP regimes, respectively (Fig. 2A).

The MDA level within the three ramets of homogeneous treatment (i.e., PPP) was higher than the roots of heterogeneous treated clones and the control (Table 2). MDA level was higher in WWP and WPW regime vs. WWW and PWW (Table 2). However, there was no difference in root MDA between WWW and PWW regimes (Table 2). Untreated ramets of PWW and WPW contained less MDA compared with PEG treated ramets. PEG treated ramet of WWP had the same root MDA level as the neighbor ramet, but higher compared with further ramet (Fig. 1B).

ENZYMe ACTIVITY. The three ramets of the control had the least mean leaf SOD activity. PWW regime within heterogeneous treatments contained the highest SOD activity compared with WPW and WWP (Table 1). PEG 6000 treated ramets in heterogeneous treatment regimes had higher SOD than the connected untreated ramets. The SOD activity in all three ramets within homogeneous regimes and the control was the same (Fig. 3A).

Generally, PEG treated roots had higher mean SOD activity in the heterogeneous and homogeneous regimes vs. the control. Root ramets of WPW contained a higher level of SOD activity compared with PWW and WWP regimes (Table 2). Within
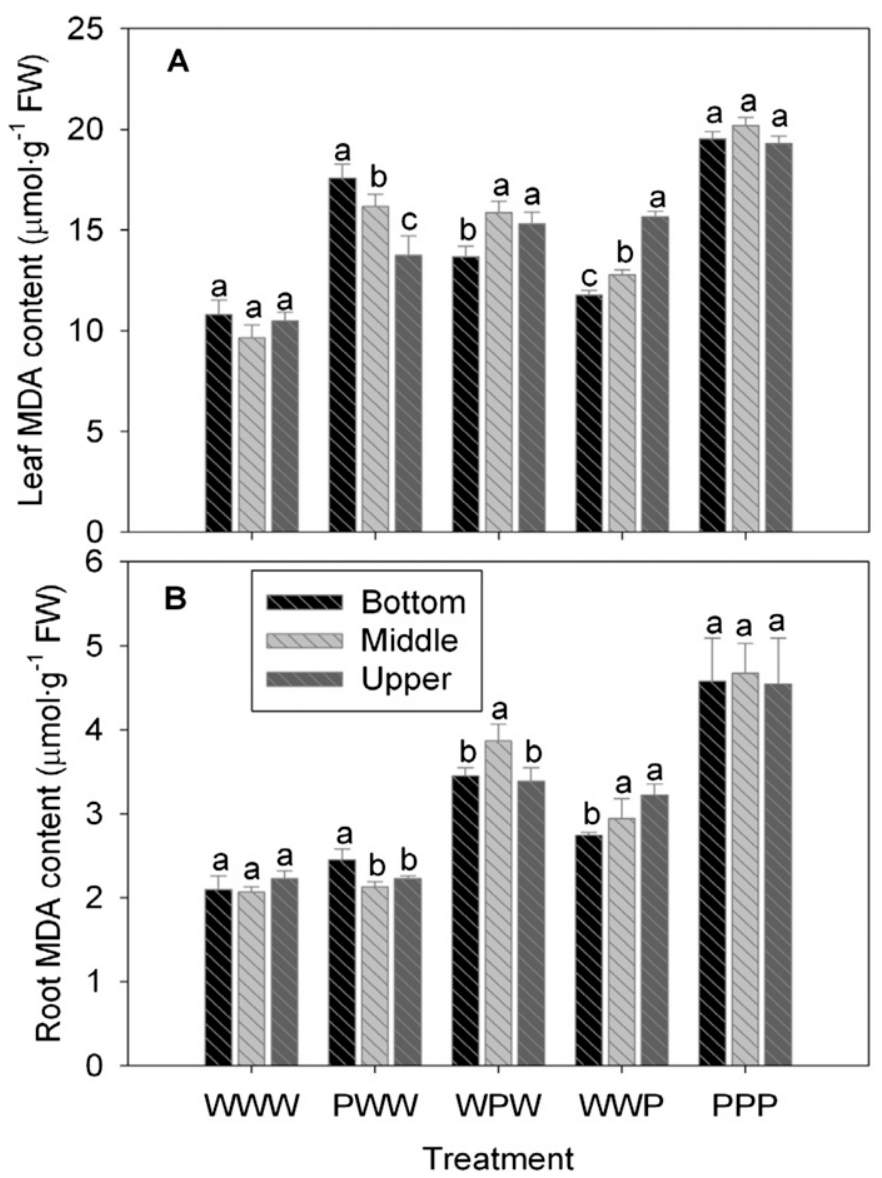

Fig. 2. (A) Leaf and (B) root malonaldehyde (MDA) content of supporting and dependent ramets in clonal common bermudagrass under heterogeneous water treatments. The bars are means $\pm \mathrm{SD}(n=3)$. Columns marked with different letters in a treatment were significantly different based on Duncan's test $(P \leq 0.05)$; W indicates nutrient solution; $\mathrm{P}$ indicates polyethylene glycol $(20 \%$ PEG 6000) resolved in nutrient solution. (Bottom ramet is the one on the left side, upper ramet is on far right, while the middle ramet is at the center. This indicates the direction of growth of the clonal ramets from bottom to up). 
Table 2. Effects of contrast level of water availability on root physiological parameters in clonal common bermudagrass.

\begin{tabular}{lrrrrc}
\hline & \multicolumn{5}{c}{ Treatment $^{\mathrm{y}}$} \\
\cline { 2 - 6 } Parameters $^{\mathrm{z}}$ & $\mathrm{WWW}$ & PWW & WPW & WWP & PPP \\
\hline MDA $\left(\mu \mathrm{mol} \cdot \mathrm{g}^{-1} \mathrm{FW}\right)$ & $2.1 \mathrm{~d}^{\mathrm{x}}$ & $2.3 \mathrm{~d}$ & $3.6 \mathrm{~b}$ & $2.972 \mathrm{c}$ & $4.6 \mathrm{a}$ \\
SOD $\left(\mathrm{U} \cdot \mathrm{mg}^{-1}\right.$ protein) & $22.7 \mathrm{~b}$ & $23.1 \mathrm{~b}$ & $44.0 \mathrm{a}$ & $31.6 \mathrm{~b}$ & $31.1 \mathrm{~b}$ \\
CAT $\left(\mathrm{U} \cdot \mathrm{mg}^{-1}\right.$ protein) & $14.3 \mathrm{c}$ & $18.4 \mathrm{bc}$ & $29.1 \mathrm{a}$ & $21.8 \mathrm{abc}$ & $23.8 \mathrm{ab}$ \\
POD $\left(\mathrm{U} \cdot \mathrm{mg}^{-1}\right.$ protein) & $4.8 \mathrm{~b}$ & $6.8 \mathrm{~b}$ & $12.6 \mathrm{a}$ & $8.8 \mathrm{ab}$ & $12.3 \mathrm{a}$
\end{tabular}

$\overline{\mathrm{z}} \mathrm{MDA}=$ malonaldehyde; $\mathrm{SOD}=$ superoxide dismutase; $\mathrm{POD}=$ peroxidase; $\mathrm{CAT}=$ catalase .

${ }^{y}$ Polyethylene glycol (20\% PEG 6000) treatment layout on three connected ramets: WWW = control; PWW, WPW, and WWP indicate heterogeneous treatments where PWW $=$ bottom, WPW = middle, and WWP = upper ramets. PPP indicates homogeneously treated ramets. $\mathrm{W}$ is nutrient solution while $\mathrm{P}$ is $20 \%$ PEG 6000 resolved in nutrient solution.

${ }^{\mathrm{x}}$ Means in a row for each parameter followed by the same letter are not significantly different based on Duncan's test $(P \leq 0.05)$.
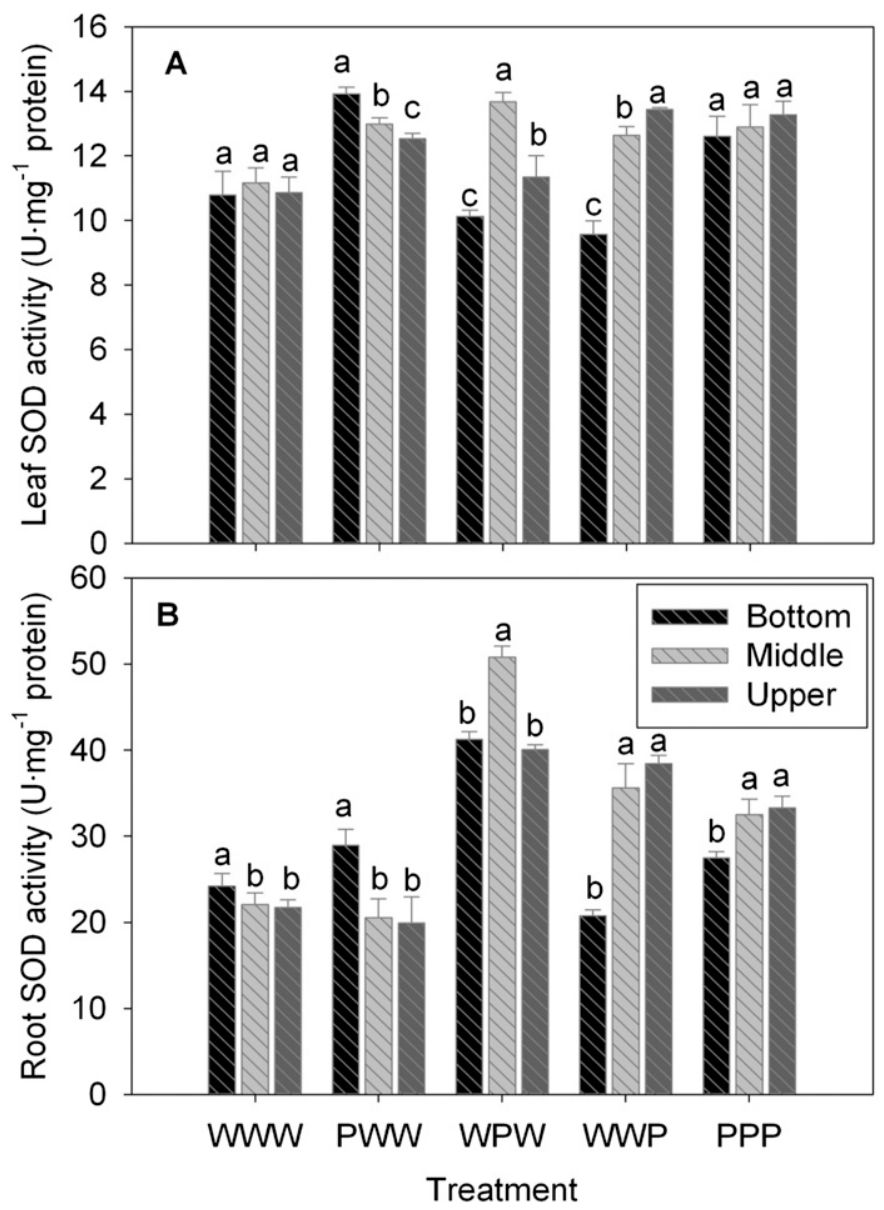

Fig. 3. (A) Leaf and (B) root superoxide dismutase (SOD) activity of supporting and dependent ramets in clonal common bermudagrass under heterogeneous water treatment. The bars are means $\pm \mathrm{SD}(n=3)$. Columns marked with different letters in a treatment were significantly different based on Duncan'stest $(P \leq 0.05)$; W indicates nutrient solution; $\mathrm{P}$ indicates polyethylene glycol (20\% PEG 6000) resolved in nutrient solution.

PWW and WPW regimes the PEG treated ramets had higher SOD activities compared with their connected untreated neighbors. The SOD activity in treated (i.e., upper) ramet of WWP regime was same with middle ramet but higher than the bottom ramet (Fig. 3B).
The homogeneously or heterogeneously $20 \%$ PEG 6000 treated leaves had a lower POD level compared with the control. Connected fragments of PWW had the highest POD in regard of the heterogeneous treatments (Table 1). $20 \%$ PEG 6000 treated ramets of PWW and WWP regimes had same POD with the middle, but higher than bottom and upper ramets, respectively. On the other hand, within the three ramets of WPW and control regimes, the POD activity was the same (Fig. 4A).

The untreated roots exhibited the least root POD activity when compared with the three heterogeneous regimes. WPW had the highest POD in regard to the heterogeneous treatments (Table 2). PEG 6000 treated ramets within the heterogeneous regimes had higher POD than their untreated connected ramets. However, there was no difference in POD activities within connected ramets in control and homogeneous regime (Fig. 4B).

The three fragments of the heterogeneous regimes contained higher CAT activity compared with the control. In regard to homogeneous treatment, the heterogeneous regimes and control had the least CAT activity (Table 1). The 20\% PEG 6000 treated fragments had higher CAT activity compared with their neighbor ramets. There was no difference in CAT activities within the three fragments of the control (Fig. 5A).

The heterogeneous treatment within roots had higher mean CAT than the control. The WPW regime contained highest
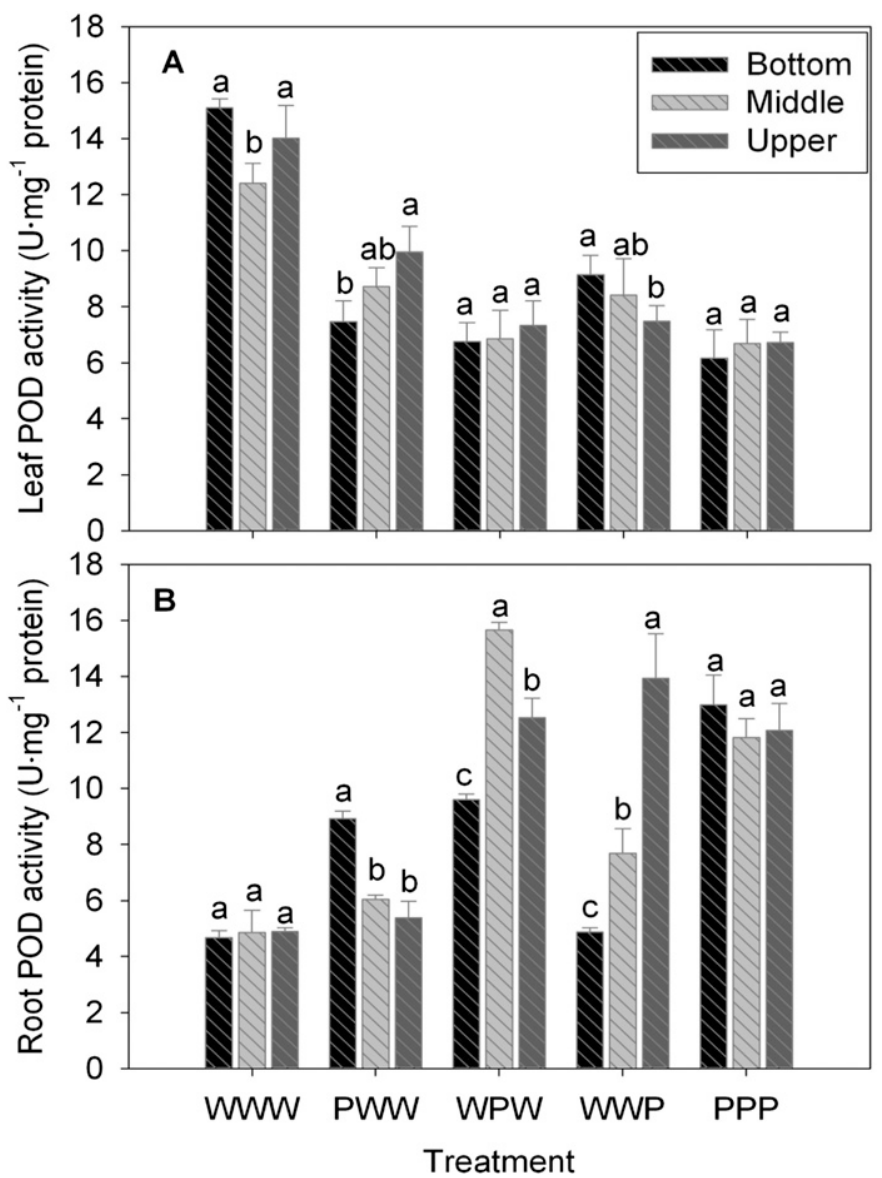

Fig. 4. (A) Leaf and (B) root peroxidase (POD) activity of supporting and dependent ramets in clonal common bermudagrass under heterogeneous water treatment. The bars are means $\pm \mathrm{SD}(n=3)$. Columns marked with different letters in a treatment were significantly different based on Duncan's test $(P \leq 0.05)$; W indicates nutrient solution; $\mathrm{P}$ indicates polyethylene glycol $(20 \%$ PEG 6000) resolved in nutrient solution. 

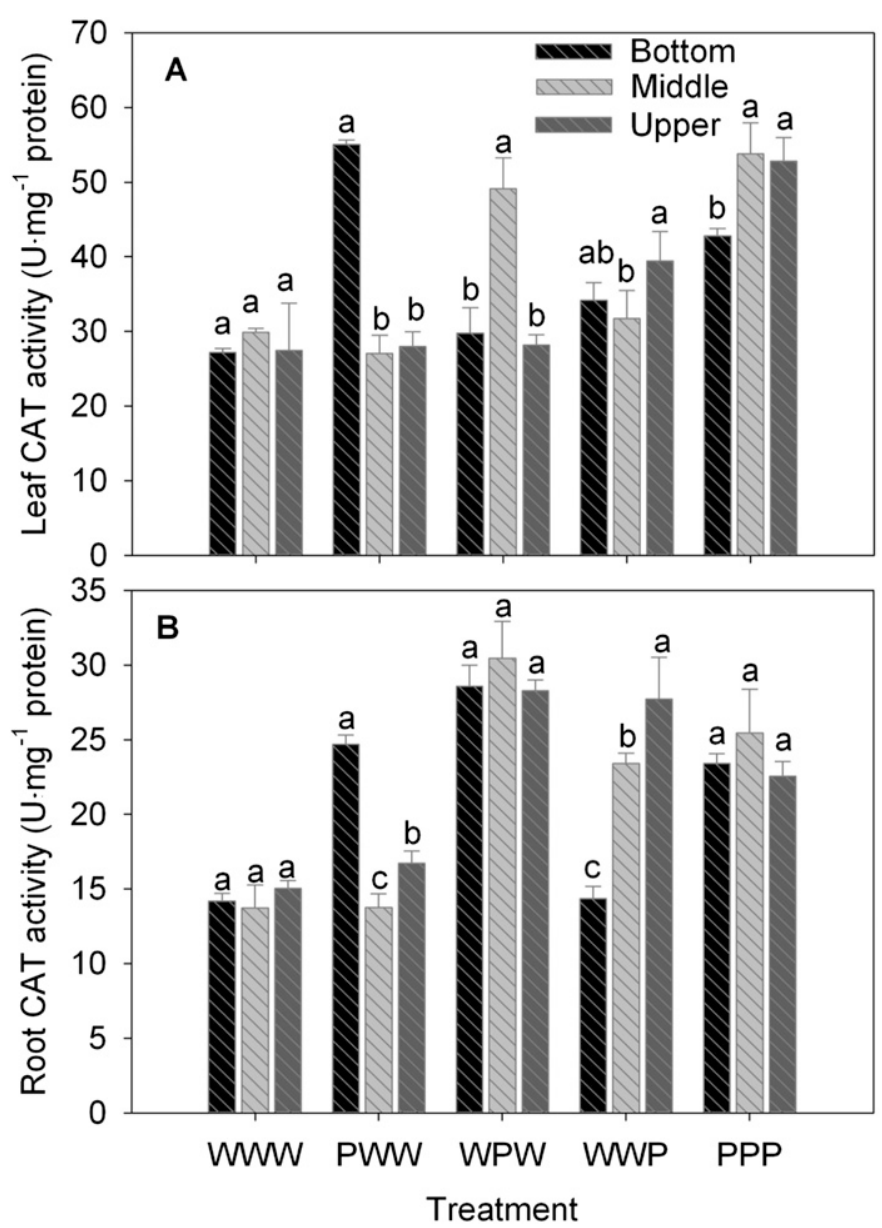

Fig. 5. (A) Leaf and (B) root catalase (CAT) activity of supporting and dependent ramets in clonal common bermudagrass under heterogeneous water treatment. The bars are means $\pm \mathrm{SD}(n=3)$. Columns marked with different letters in a treatment were significantly different based on Duncan's test $(P \leq 0.05)$; W indicates nutrient solution; $\mathrm{P}$ indicates polyethylene glycol (20\% PEG 6000) resolved in nutrient solution.

CAT in regard to heterogeneous treatment (Table 2). The PEG 6000 treated ramets of PWW and WWP had higher CAT activities compared with the respective untreated connected neighbors. However for WPW, the CAT activity was same for all the three connected fragments. There was no difference in CAT activity within the fragments of control and homogeneous regime (Fig. 5B).

\section{Discussion}

Physiological and morphological plasticity are the main factors that facilitate acquisition of materials from nonuniform habitats. Grime and Mackey (2002) and de Kroon et al. (2005) reported that plants are capable of adjusting their physiological processes precisely to overcome the specific stress. The results of this study indicated that 'C198' common bermudagrass under heterogeneous water stress could alter its antioxidant enzyme allocation pattern. The ramets under high osmotic stress maintain proportionally high investment of antioxidant enzymes in the leaves and roots. This high investment is facilitated by apparent importation of these enzymes from their connected neighbor ramets. This phenomenon is evidenced by notably higher SOD and CAT activities of leaves, roots, and root POD in 20\% PEG 6000 treated ramets compared with the connected untreated fragments and control. Connected clonal ramets in homogeneous and control treatments appear to have almost equal enzyme activities. This suggests the necessity of water stress heterogeneity in importation and exportation of antioxidant enzymes. The differences in enzyme activities in clonal fragments within heterogeneous treatments indicate that spatial distribution of supporting ramets influenced the translocation pattern of enzymes.

Sharing of antioxidant enzymes from ramets growing in normal conditions to those under water stress leads to compensation of local shortage. Sharing of antioxidant enzymes may result from overwhelming demand for synthesis and transportation of more antioxidant enzymes in the stressed ramets in an effort to scavenge ROS as explained by Marshall (1990) and Birch and Hutchings (1994). This response mechanism allows compensatory growth under osmotic stress caused by drought. Therefore, higher CAT activity in leaves than roots is a reflection of higher investment in leaves to protect the photosynthetic machinery against harmful effects of ROS. While higher SOD activities in the roots could be a strategy to protect the water absorption machinery in the roots ensuring there is maximum water absorption. These observations are consistent with division of labor concept reported by Stuefer (2005), and are confirmed to secure the entire clonal plant from oxidative damage.

SOD is the first detoxification enzyme that catalyzes ROS to $\mathrm{H}_{2} \mathrm{O}_{2}$ and $\mathrm{O}_{2}$. Enhanced SOD activities have been observed in various plants to improve tolerance against osmotic stress (Bakalova et al., 2004; Malecka et al., 2001). Osmotic stress tolerance contributes significantly toward protecting the plant from the toxic effects of ROS (Gill and Tuteja, 2010). Higher constitutive SOD activities in the roots indicated that roots had a higher dismutating capacity than leaves.

In this experiment we observed that CAT activity increased with increase in SOD activity. Particularly, this is evidenced by direct proportionality in the allocation patterns of the enzymes within the connected ramets. The remarkable increase in mean CAT activity within heterogeneous treatment suggested a strong induction in the $\mathrm{H}_{2} \mathrm{O}_{2}$ concentration as a result of dismutation activity of SOD. Therefore, this observation was consistent with suggestion that a balance between SOD and CAT activity was crucial for efficient ROS scavenging (Mona, 2014). Similarly with nonclonal plants, high leaf CAT activity in the homogeneous treatment indicates the plants encountered higher osmotic stress. This stress resulted in higher CAT production compared with the control. However, even with lower CAT levels, heterogeneous treatments and the control experienced lower osmotic damage as indicated by lower MDA levels within the heterogeneous treatment than homogeneous treatment. This observation suggested that ROS scavenging was more efficient in heterogeneous treatment and that elevated CAT levels in homogeneous treatments could not achieve maximum ROS scavenging. Leaf POD activity did not seem to influence dismutation process in 'C198' common bermudagrass. This was evidenced by minimum POD activity within the heterogeneous and homogeneous treatments. However, this did not suppress ROS scavenging as evidenced by decline in MDA levels in the heterogeneous treatment compared with the control. Guaiacols are heme containing bifunctional enzymes participating in numerous physiological processes in plants. 
Lila et al. (2007) explained that its expression pattern is organ specific and developmentally regulated. Therefore POD could be participating in a range of other physiological processes (e.g., cell elongation, wall construction and cross linking of cell wall constituents, lignin polymerization, and auxin catabolism) to overcome drought-induced leaf growth reduction (Passardi et al., 2004). Increase in POD activity in response to ROS production under osmotic stress has been documented in cotton [Gossypium hirsutum (Gussett et al., 1994)], tobacco [Nicotiana tabacum (Das and Uprety, 2006)], and durum wheat [Triticum durum (Csiszar, 2005)].

Apparently, osmotically stressed clonal fragments received considerable benefits of physiological integration at the cost of untreated ones. The benefit was more when the stressed fragment was between two untreated fragments (middle), as observed in leaf CAT, SOD, and root POD. This is based on the observation that in both root and leaves the middle fragment experienced high antioxidant activities as observed by increase in leaf CAT and SOD and root POD. In our study, the 'C198' drought stressed ramets behaved like strong sinks and wet ramets like sources for antioxidant enzymes. The contrast in patchiness acted as an external driver of enzymes integration as observed in resource allocation studies by Stuefer et al. (1996). Enzyme integration was influenced by directionality in the clone and seemed to be driven by water potential gradient as described by deKroon (1996). Integration for the supporting ramets had cost in general as observed by lower antioxidant enzymes activities in connected untreated ramets compared with treated regimes. However, the net benefits at whole clone level outweighed the cost as evidenced by clear decline in MDA levels within heterogeneous treatment.

Our results were consistent with previous studies, which indicated that leaves are more sensitive to osmotic stress than roots (Boyer, 1968; Westgate and Boyer, 1985). This was observed via generally higher MDA levels in leaves than in roots. However, this MDA content was significantly lower in heterogeneous treatments compared with the homogeneous regimes of leaves and roots. This suggests that clonal integration is necessary in ameliorating lipid peroxidation hence enhancing the survival of the entire clone.

The overall response of 'C198' common bermudagrass to heterogeneously available water reflected the combined contributions of each ramets' plastic response to patchy water availability as observed by deKroon et al. (2009). When clonal plants grow under heterogeneous conditions, they display modular division of labor. Each ramet specializes to acquire locally available resources. From our results, different enzyme allocation patterns suggested that under natural environment, ramets of clonal bermudagrass were not placed randomly. Their positioning might be constrained by architectural and developmental plan influenced by water heterogeneity (Bell, 1984; Huber et al., 1999; Jonsdottir and Watson, 1997; Mogie and Hutchings, 1990).

In summary, clonal integration was crucial for antioxidant enzyme integration, especially when salt-sensitive ' $\mathrm{C} 198$ ' common bermudagrass is growing under heterogeneous water stress. The net benefit of this clonal integration was to enable the entire clone to achieve maximum drought stress tolerance. Therefore, antioxidant enzymes integration in clonal common bermudagrass was integral during response to patchy drought stress. Clonal integration can be understood as part of stress tolerance strategy that can enhance the survival and growth of clonal common bermudagrass growing in patchy environment. This study adds novel information concerning the physiological and morphological mechanisms of drought tolerance. The findings are significant for turfgrass management systems.

\section{Literature Cited}

Aebi, H. 1984. Catalase in vitro. Methods Enzymol. 105:121-126.

Alpert, P. 1991. Nitrogen sharing among ramets increases clonal growth in Fragaria chiloensis. Ecology 72:69-80.

Alpert, P. and J. Stuefer. 1997. Division of labor in clonal plants, p. 137-154. In: H. de Kroon and J. van Groenendael (eds.). The ecology and evolution of clonal plants. Backhuys, Leiden, The Netherlands.

Bakalova, S., A. Nikolova, and D. Wedera. 2004. Isoenzyme profiles of peroxidase, catalase and superoxide dismutase as affected by dehydration stress and ABA during germination of wheat seeds. J. Plant Physiol. 30:64-77.

Bazihizina, N., T.D. Colmer, and E.G. Barret-Lennard. 2009. Response to non-uniform salinity in the root zone of the halophyte Atriplex nummularia: Growth, photosynthesis, water relations and tissue ion concentrations. Ann. Bot. 104:737-745.

Becana, M., P. Aparicio-Tejo, J.J. Irigoyen, and M. Sanchez-Diaz. 1986. Some enzymes of hydrogen peroxide metabolism in leaves and root nodules of Medicago sativa. Plant Physiol. 82:1169-1171.

Bell, A.D. 1984. Dynamic morphology: A contribution to plant population ecology, p. 48-65. In: R. Dirzo and J. Sarukhan (eds.). Perspectives on plant population ecology. Sinauer, Sunderland, MA.

Birch, C.P. and M.J. Hutchings. 1994. Exploitation of patchily distributed soil resources by the clonal herb Glechoma hederacea. J. Ecol. 82:653-664.

Boyer, J.S. 1982. Plant productivity and environment. Science 218:443-448.

Boyer, J.S. 1968. Relationships of water potential to growth of leaves. Plant Physiol. 43:1056-1062.

Bradford, M.M. 1976. A rapid and sensitive method for quantitation of microgram quantities of protein utilizing the principle of proteindyebinding. Ann. Biochem. 72:248-254.

Carvalho, C. and M. Helena. 2008. Drought stress and reactive oxygen species: Production, scavenging and signaling. Plant Signal. Behav. 3:156-165.

Chapman, D.F., M.J. Robson, and R.W. Snaydon. 1991. The influence of leaf position and defoliation on the assimilation and translocation of carbon in white clover (Trifolium repens). Ann. Bot. 67:303-308.

Csiszar, J. 2005. Effect of osmotic stress on antioxidant enzyme activities in transgenic wheat calli bearing mSalr gene. Acta Biologica Szegediensis 49:49-50.

D'Hertefeldt, T. and I.S. Jónsdóttir. 1994. Effects of resource availability on integration and clonal growth in Maianthemum bifolium. Folia Geobot. Phytotaxon. 29:167-179.

Das, R. and D. Uprety. 2006. Interactive effect of moisture stress and elevated $\mathrm{CO}_{2}$ on the oxidative stress in Brassica species. J. Food Agr. Environ. 4:298-305.

de Kroon, H., H. Huber, J.F. Stuefer, and J.M. van Groenendael. 2005. A modular concept of phenotypic plasticity in plants. New Phytol. 166:73-82.

deKroon, H. 1996. High levels of inter-ramet water translocation in two rhizomatous Carex species, as quantified by deuterium labelling. Oecologia 106:73-84.

deKroon, H., E.J. Visser, H. Huber, L. Mommer, and M.J. Hutchings. 2009. Modular concept of plant foraging behavior: The interplay between local responses and systemic control. Plant Cell Environ. 32:704-712.

Gao, S., R. Yan, C. Yang, W. Wang, and S. Chen. 2008. Effects of copper on growth, antioxidant enzymes and phenylalanine ammonia-lyase activities in Jatropha curcas. seedling. Plant Soil Environ. 54:117-122. Gill, S. and N. Tuteja. 2010. Reactive oxygen species and antioxidant machinery in crop plants. Plant Physiol. Biochem. 48:909-930. 
Grime, J.P. and J.M. Mackey. 2002. The role of plasticity in resource capture by plants. Evol. Ecol. 16:299-307.

Gussett, D.R., E.P. Miliholon, and M.C. Lucas. 1994. Antioxidant response to $\mathrm{NaCl}$ stress-tolerant and salt sensitive cultivar of cotton. Crop Sci. 34:706-714.

Heath, R. 1968. Photoperoxidation in isolated chloroplasts: Kinetics and stoichiometry of fatty acid peroxidation. Arch. Biochem. Biophys. 125:189-198.

Hoagland, D.R. and D.I. Arnon. 1950. The water-culture method for growing plants without soil. California Agr. Expt. Sta. Circ. 347:1-32.

Hu, T., H.Y. Li, X.Z. Zhang, H.J. Luo, and J.M. Fu. 2011. Toxic effect of $\mathrm{NaCl}$ on ion metabolism, antioxidative enzymes and gene expression of perennial ryegrass. Ecotoxicol. Environ. Saf. 74:2050-2056.

Huber, H., S. Lukács, and M.A. Watson. 1999. Spatial structure of stoloniferous herbs: Interplay between structural blue-print, ontogeny and phenotypic plasticity. Plant Ecol. 141:107-115.

Hutchings, M.J. and H. de Kroon. 1994. Foraging in plants: The role of morphological plasticity in resource acquisition. Adv. Ecol. Res 25:159-238.

Jaleel, C.A., A. Manivannan, M. Wahid, R. Farooq, R. Somasundaram, and R. Panneerselvam. 2009. Drought stress in plants: A review on morphological characteristics and pigments composition. Intl. J. Agr. Biol. 11:100-105.

Jonsdottir, I.S. and M.A. Watson. 1997. Extensive physiological integration: An adaptive trait in resource-poor environments? p. 109-136. In: H. de Kroon and J. van Groenenndael (eds.). The ecology and evolution of clonal plants. Backhuys, Leiden, The Netherlands.

Kemball, W.D. and C. Marshall. 1995. Clonal integration between parent and branch stolons in white clover: A developmental study. New Phytol. 125:513-521.

Kliměs, L., J. Kliměsova, R. Hendriks, and J. van Groenendael. 1997. Clonal plant architecture-A comparative analysis of form and function, p. 1-29. In: H. de Kroon and J. van Groenendael (eds.). The ecology and evolution of clonal plants. Backhuys, Leiden, The Netherlands.

Kuo, M.C. and C.H. Kao. 2003. Aluminium effects on lipid peroxidation and antioxidative enzyme activities in rice leaves. Biol. Plant. 46:149-152.

Lau, R.R. and D.R. Young. 1988. Influence of physiological integration on survivorship and water relations in clonal herb. Ecology 69:215-219.

Lila, G., K. Ezzatolah, and G. Shokoofeh. 2007. Kinetics properties of guaiacol peroxidase activity in Crocus sativus L. corm during rooting. Iran. Biomed. J. 11:137-146.

Lin, K., C.M. Chao, W.C. Yang, H.F. Cheng, and T.R. Chang. 2006. The effects of flooding and drought stresses on the antioxidant constituents in sweet potato leaves. Bot. Stud. 47:417-426.

Maas, E. and G.J. Hoffman. 1977. Crop salt tolerance-current assessment. J. Irr. Drainage 103:115-132.

Malecka, A., W. Jarmuszkiewicz, and B. Tomaszewska. 2001. Antioxidative defense to leaf stress in subcellualr compartment of pea root cells. Acta Biochim. Pol. 48:687-698.

Marcum, K.B. and C.L. Murdoch. 1994. Salinity tolerance mechanisms of six C4 turf grasses. J. Amer. Soc. Hort. Sci. 119:779-784. Marshall, C. 1990. Source-sink relations of interconnected ramets, p. 23-41. In: J. van Groenendael and H. de Kroon (eds.). Clonal growth in plants-regulation and function. SPB Academic, The Hague, The Netherlands.
Mittler, R.S., M. Vanderauwera, and F. Van Breusegem. 2004. Reactive oxygen gene network of plants. Trends Plant Sci. 9:490 498

Mogie, M. and M.J. Hutchings. 1990. Clonal growth in plants: Regulation and function, p. 3-22. In: J. van Groenendael and H. de Kroon (eds.). Phylogeny, ontogeny, and clonal growth in clonal plants. SPB Academic, The Hague, The Netherlands.

Mona, K. 2014. Antioxidant profiling of some important medicinal plants. Intl. J. Sci. Res. 3:49-53.

Oborny, B., A. Kun, T. Czaran, and S. Bokros. 2000. The effect of clonal integration on plant competition for mosaic habitat space. Ecology 81:3291-3304.

Palmer, H. and K.E. Paulson. 1997. Reactive oxygen species and antioxidants in signal transduction and gene expression. Nutr. Rev. 55:353-361.

Parker, M.A. and A.G. Salzman. 1985. Herbivore exclosure and competitor removal: Effects on juvenile survivorship and growth in the shrub Gutierrezia microcephala. J. Ecol. 73:903-913.

Passardi, F., D. Longet, C. Penel, and C. Dunand. 2004. The class III peroxidase multigenic family in rice and its evolution in land plants. Phytochemistry 65:1879-1893.

Roiloa, S.R. and R. Retuerto. 2005. Presence of developing ramets of Fragaria vesca $L$. increases photochemical efficiency in parent ramets. Intl. J. Plant Sci. 166:795-803.

Roiloa, S.R. and R. Retuerto. 2006. Small-scale heterogeneity in soil quality influences photosynthetic efficiency and habitat selection in a clonal plant. Ann. Bot. 98:1043-1052.

Roiloa, S.R. and M. Hutchings. 2013. The effects of physiological integration on biomass partitioning in plant modules: An experimental study with the stoloniferous herb Glechoma hederacea. Plant Ecol. 214:521-530.

Shumway, S.W. 1995. Physiological integration among clonal ramets during invasion of disturbance patches in a New-England salt-marsh. Ann. Bot. 76:225-233.

Silander, J., Jr. and S.W. Picala. 1990. The application of plant population dynamic models to understanding plant competition, $\mathrm{p}$. 67-91. In: J.B. Grace and D. Tilman (eds.). Perspectives on plant competition. Academic Press, San Diego, CA.

Sovenneveld, C. and C. de Kreij. 1999. Response of cucumber (Cucumis sativus L.) to an unequal distribution of salt in the root environment. Plant Soil 209:47-56.

Stuefer, J., H. De Kroon, and H.J. During. 1996. Exploiation of environmental heterogeneity by spatial division of labour in clonal plant. Funct. Ecol. 10:328-334.

Stuefer, J. 2005. Exploitation of environmental heterogeneity by spatial division of labor in clonal plant. New Phytol. 166:73-82.

Tabatabaie, P.J. and P. Gregory. 2004. Uneven distribution of nutrients in the root zone affects the incidence of blossom end rot and concentration of calcium and potassium in fruits of tomato. Plant Soil 258:169-178.

Wang, Z., Y. Zhang, Z. Huang, and L. Huang. 2008. Antioxidative response of metal-accumulator and non accumulator plants under cadmium stress. Plant Soil 301:137-149.

Westgate, M.E. and J.S. Boyer. 1985. Osmotic adjustment and the inhibition of leaf root, stem and silk growth at low water potentials in maize. Planta 164:540-549.

Wu, Q., Y.N. Zou, R.X. Xia, and M.Y. Wang. 2007. Five Glomus species affect water relations of citrus tangerine during drought stress. Bot. Stud. 48:147-154. 